\title{
Research on Domestic and Foreign Advanced Manufacturing Development Policy
}

\author{
Dong Liang ${ }^{1}$ and Zhongwei Zhang ${ }^{2, *}$ \\ 1Jianghan University Business School, Wuhan \\ ${ }^{2}$ Jianghan University Business School, Wuhan \\ 1925243770@qq.com, ${ }^{2 *} 1039857158 @ q q . c o m$ \\ * The corresponding author
}

Keywords: Advanced manufacturing; Competitive advantage; Government support policy

\begin{abstract}
The core of the advanced manufacturing industry lies in its "advancedness", which is reflected not only in the advanced nature of the technology, but also in the advanced nature of the industry and the advanced management. Innovation in advanced manufacturing is an important part of a country's economic competitiveness, a key area for participating in international competition and highlighting national competitive advantages, and it is also an important carrier for innovative applications and breakthroughs in innovation. Based on this, this paper analyzes the supporting policies of the advanced manufacturing industries in the United States, Germany, and Japan, sums up the key trends of foreign government support policies and Under the premise of combining the government support policies of China's advanced manufacturing industry, it is pointed out that accelerating the development of China's manufacturing industry needs to be carried out by promoting technological innovation, perfecting personnel training mechanisms, developing green manufacturing, and promoting clustering.
\end{abstract}

\section{Preface}

Since entering the 21 st century, the manufacturing industry is facing the opportunities and challenges brought about by the adjustment of global industrial structure. In particular, after experiencing the financial crisis in 2008, countries began to face the pressure of transformation and upgrading of the manufacturing industry. In order to find new ways to promote economic growth, all countries have begun to re-emphasize the development of advanced manufacturing. In 2011, the United States proposed the "Advanced Manufacturing Partner Program" to increase investment in technological innovation. After China's reform and opening up, China has established a clear advantage in the international market with the rapid development of manufacturing. However, the traditional mode of extensive manufacturing has gradually lost its advantages. Using advanced technology as a means of production is an inevitable trend in the future development of manufacturing. Faced with this situation, China's manufacturing industry must rise to the chase. Neither can it abandon its advantages in the traditional manufacturing industry, but also actively compete for the commanding heights of advanced manufacturing.

\section{Analysis of Foreign Support Policies for Advanced Manufacturing Industries}

U. S. Advanced Manufacturing Strategy Development Policy. In order to revitalize the manufacturing industry, the U. S. government has issued a series of policy measures to support the development of the manufacturing industry, especially the advanced manufacturing industry, through financial support, guiding investment, tax relief, and improving the quality of laborers. The United States has issued specific policies centering on technology research and development, technology transfer, tax incentives, and talent education special funds, and has invested a lot of funds to accelerate the strategy. In terms of technology research and development policies, the U. S. government has played a leading role in establishing innovative research institutions and pilot applications, and has opened up the "Basic R\&D-Application Research-Industrialization" 
innovation chain of advanced manufacturing technologies. In the basic research and development, build a center of excellence and innovation. The construction of a manufacturing innovation network in the applied research link and the manufacturing technology test bed in the industrialization link. In addition, the U. S. government has also supported the Industrial Alliance to develop a technology roadmap by launching the Advanced Manufacturing Technology Alliance project, which will reduce the barriers to the development of advanced manufacturing in the United States.

In terms of technology transfer policies, the U. S. government has expanded its alliance program, manufacturing community partner investment program, and manufacturing technology acceleration center through the manufacturing industry in order to help the latest innovative manufacturing technology gain commercial value and enable it to rapidly realize the industrialization of technology. Accelerate technology transfer. Moreover, the U. S. government promotes the transfer of manufacturing to the United States through tax reform of advanced manufacturing companies, reducing the tax rate of advanced manufacturing companies from $35 \%$ to $25 \%$, and ending the tax incentives for overseas outsourcing of enterprises to encourage and support manufacturing business investment in the United States. In addition, the U. S. government has also mobilized social capital extensively to encourage manufacturing-related companies in the manufacturing industry to set up special funds to attract overseas U. S. manufacturing companies to return to local investment. In terms of personnel education, the U. S. government has invested nearly one billion U. S. dollars in community colleges to train qualified workers for advanced manufacturing.

Germany Implements Industry 4. 0 Strategy. Industry 4. 0 is a strategy proposed by Germany in the face of the manufacturing revolution in an effort to maintain the continuous leadership of German manufacturing in the world. In order to promote the industrial 4. 0 strategy, Germany has released a series of technology research and development policies, technology transfer policies and supporting policies. The German Ministry of Education and Research spent a lot of money to promote the research of Industry 4. 0, and has already approved 120 million euros. Major projects include standards and reference systems, industry 4. 0 applications in SMEs, information technology security and staff qualifications.

In March 2016, the German government released the “Digital Strategy 2025” , and part of the infrastructure investment amounted to 100 billion euros. It aims to provide momentum for the construction of the Industry 4. 0 system by strengthening the construction of digital technology facilities and boosting economic growth. In addition, the German Ministry of Teaching and Research has also successively released fields that are closely related to Industry 4. 0, and supports enterprises and universities in carrying out research and giving certain subsidies. In terms of human resources, the German government has established a comprehensive talent education and training system and has formulated a complete talent training plan. There are corresponding measures in various links such as production, education, research, and basic skills. There are about 200 universities of applied sciences in Germany engaged in scientific research, aiming at cultivating practical talents for advanced manufacturing.

Japanese Government Promotes Smart Manufacturing Development Policy. While the concepts of advanced manufacturing and industrial 4. 0 have swept across the globe and triggered the global smart manufacturing fever, although the Japanese government has not clearly put forward the relevant strategies for smart manufacturing, it still attaches great importance to the development of advanced manufacturing industries and actively introduces measures to reverse the decrease in the proportion of manufacturing. Situation, the information and communication, energy conservation and other industries as the country's key areas of cultivation. In particular, funding and research on projects such as manufacturing informatization, information physics integration systems, big data, and 3D printers have been strengthened. In terms of technology research and development, the Japanese government provides financial support for specific research areas. In the field of 3D printing technology, the Japanese government listed 3D printers as a priority policy support target in 2014, and invested 4. 5 billion yen in the year. In the field of robotics, the "New Strategy for Robotics" was released in 2015. It is proposed that in the next five years, various policies including 
the reform of the government system will be applied to the maximum, and investment in the development of robots will be expanded, and a 100 billion yen robot support project will be promoted. . In the field of artificial intelligence, a government budget of 10 billion yen is invested to support the research on artificial intelligence of research institutes and universities.

In the field of talent cultivation, the Japanese government provides training for departing people, working people, and college graduates, develops public vocational abilities, and pays a certain percentage of the costs for laborers who have completed advanced manufacturing technology education and training at their own expense. In respect of the tax exemption, the Japanese government's research funding for the trials is reduced according to the $8 \%$ to $10 \%$ tax of the experimental research funds. For R\&D activities carried out by small and medium-sized enterprises, $12 \%$ of the experimental research funds are waived. Moreover, in order to promote Japanese SMEs to invest in equipment, when purchasing certain machinery and equipment, $30 \%$ depreciation or $7 \%$ tax deductions are provided for the acquisition cost of SMEs.

Policy Trends in the United States, Germany, and Japan. Pay Attention to Technology Research and Development. The advanced manufacturing policies of various countries have put technology research and development into a very important position. The "Industry 4. 0 " strategy of Germany places special emphasis on the intelligent transformation of manufacturing industries. It plans to launch eight projects including industrial broadband infrastructure, management systems, and regulatory framework. It fully integrates information physics systems and information and communication technologies, and focuses on the development of intelligent factories, intelligence production and intelligent logistics, researching the intelligent production process, integrating logistics resources, and improving the efficiency of resource providers through the use of networks, to realize the horizontal integration of value chains among enterprises, the vertical integration of networked manufacturing systems, and the integration of the entire value chain from end to end aims.

In the EU-funded "IMS2020 Plan," it is proposed that key technologies and standardization areas should be emphasized, energy-saving manufacturing and sustainable manufacturing should be achieved through technological research and development, and short-term goals, long-term goals and a 15-year smart manufacturing blueprint should be gradually planned. the Japanese government has also proposed a plan to increase the degree of information technology in manufacturing to more than $50 \%$, accelerate the penetration of advanced information technology, and realize the upgrading of the manufacturing industry. the U. S. "National Strategic Plan for Advanced Manufacturing Industry" will increase R\&D investment as an important goal, and incentivize R\&D through the strengthening and perpetuation of research and test tax credits, through the United States National Science Foundation (NSF), the Department of Energy, and the National Institute of Standards and Technology (NIST), and other institutions to provide funding for advanced manufacturing research and development, thereby reducing the company's production upgrade, accelerate product development.

Pay Attention to Personnel Training. Talent is an important driving force for the transformation of manufacturing innovation in the future. In the "Reinvigoration of manufacturing" measures introduced by the Japanese government, it is mentioned that a large number of manufacturing talents must be trained. The government finances the use of talents with special skills as experts to train front-line technicians and manufacturing workers to achieve the inheritance of production know-how and traditional manufacturing techniques. The EU "IMS2020 Plan" also emphasizes development plans for innovation training. One of the important goals of the United States' "National Strategic Plan for Advanced Manufacturing" is to improve the skills of the workforce. It also proposed specific measures such as the timely updating of the manufacturing labor force, the training of advanced manufacturing workers, the provision of vocational education for future workers, and support for the new manufacturing apprenticeship program, thereby meeting the labor needs of SMEs.

Emphasis on cooperation and integration. Cooperation and integration is an important guarantee for continuous innovation and sustainable development in the manufacturing industry. The Japanese 
government established the "Different Industries Exchange and Cooperation Conference" to promote the mutual integration of different manufacturing industries and create new markets and fields. Such as energy and information, automotive and electronics, etc. The United States' "National Strategic Plan for Advanced Manufacturing Industry" proposes that a sound partnership should be established, and around this goal, SMEs should be encouraged to participate in the partnership. Supporting cross-sector partnerships to enhance "industry commons" and through the creation of regional clusters to coordinate strategic planning, asset procurement, and risk sharing within the cluster.

Different countries have different characteristics in their development policies for advanced manufacturing. For example, the United States' Strategic Plan for Advanced Manufacturing Countries will also accelerate the investment in SMEs as an important goal, and propose that this goal should be achieved by changing investment behavior. Such as coordinating public and private investment in advanced manufacturing, increasing government's early procurement, and strengthening the improvement of shared infrastructure. Japan proposed that attention should be paid to the retention of domestic technology development mechanisms, talent training systems, and unique operating methods, and be combined with overseas production systems to ensure the vitality of Japanese manufacturing. As the basis of the national economy, the economic value created by manufacturing has always occupied a large proportion in the entire social wealth system. Advanced manufacturing technology is the precondition for the development of the manufacturing industry.

\section{Analysis of Domestic Support Policies for Advanced Manufacturing Industry}

Various countries have paid great attention to the role of government support. Through the formulation of a series of policy measures, actively promote the development, demonstration and application of key technologies in advanced manufacturing industries and strategic emerging industries. To promote the development of advanced manufacturing industries, smart manufacturing technologies and strategic emerging industries to create a good market environment.

The Development Status of China's Advanced Manufacturing Industry. As China's economy has entered the "new normal," a variety of social problems have begun to escalate, such as high prices, rapid price increases, and severe link pollution. The Chinese government has taken active measures to promote the transformation and upgrading of the manufacturing industry in the face of the problems in the manufacturing industry. "Made in China 2025" is a strategic plan made by the Chinese government in a comprehensive analysis of the current situation of the development of advanced manufacturing at home and abroad. As China's existing resources are difficult to support the development of traditional manufacturing industries, the traditional manufacturing industry is in urgent need of transformation, and the rising production costs of labor, raw materials and other products have made the competitive advantages of manufacturing products drop. This has led some developed countries to relocate their advanced manufacturing industries to cheaper Southeast Asian countries for production. Meanwhile, environmental issues have become prominent, production costs have increased, and water pollution and air pollution caused by traditional manufacturing have caused dissatisfaction among the domestic public. Traditional manufacturing companies need to find new development paths.

With the support of national policies in recent years, China's advanced manufacturing industry has improved. However, compared with the world's advanced level, China's manufacturing industry is still large but not strong and there is a clear gap in independent innovation capability, resource utilization efficiency, industrial structure level, informationization level, and quality effectiveness. The task of transformation, upgrading and leapfrog development is urgent and arduous. In recent years, developed countries such as the United States and Germany have increasingly focused on the development of advanced manufacturing industries and have successively introduced bills to revitalize the development of advanced manufacturing industries. Against this backdrop, our government is also actively transforming itself from a "manufacturing power" to a "manufacturing powerhouse" and achieving leapfrog development in advanced manufacturing. 
Analysis of China's Advanced Manufacturing Support Policies. The U. S. government has focused on key areas such as robotics, 3D printing, new materials, information technology, and biotechnology that have led the development of the world's manufacturing industry, ensuring continuous technological innovation, and leading the way into the development trend of the manufacturing industry. Like the United States, in order to cope with the arrival of the third industrial revolution, The government of our country combines China's national conditions, focusing on innovation-driven, intelligent transformation, strengthening the foundation, green development, talent-based and other key links, as well as advanced manufacturing, high-end equipment and other key areas. It has proposed major strategic tasks and major policy initiatives to speed up the transformation and upgrading of the manufacturing industry, increase efficiency, and strive to enter the ranks of manufacturing powerhouses by 2025. "Made in China 2025" is an effort and attempt to promote the transformation of China from a manufacturing powerhouse to a manufacturing powerhouse. The Chinese government put forward the basic policy of "innovation-driven, quality first, green development, structural optimization, and talent-based" in the document. It also proposed nine key tasks such as improving the country's manufacturing innovation capability, promoting the deep integration of informatization and industrialization, strengthening industrial infrastructure capabilities, strengthening quality brand building, and fully implementing green manufacturing.

To make the "Made in China 2025" plan achieve the expected results, some key issues need to be solved, Including the implementation of innovation-driven development strategy, the construction of new economic infrastructure, the allocation of resources to the real economy, the dynamic adjustment of key technologies and field catalogues, and the promotion of "artisan spirit" to strengthen the training of skilled personnel. As well as drawing on international experience, China will enter the "first square" of advanced manufacturing and become a manufacturing power. "Made in China 2025" based on the trend of international industrial change, has made a major strategic plan to comprehensively upgrade the quality and level of China's manufacturing industry development, promote the adjustment and reform of China's industrial structure, accelerate the development of China's advanced manufacturing industry, and enhance China's manufacturing industry. International competitiveness has made China an important manufacturing power, Accelerating the development of China's advanced manufacturing industry, increasing the international competitiveness of China's manufacturing industry, and making China a manufacturing powerhouse are of great significance.

Development Trend of China's Advanced Manufacturing Industry. With the impact of economic globalization, the development of advanced manufacturing is developing toward the trend and direction of intelligence, high-end, lean, and green. With the continuous adjustment and upgrading of the advanced manufacturing industry structure, the market size of China's smart manufacturing equipment continues to expand in recent years. Smart manufacturing is one of the innovative trends in advanced manufacturing. Developed countries such as Europe and the United States have emphasized the importance of smart manufacturing in their advanced manufacturing development plans, and have formulated detailed technological innovation plans and incentives. Therefore, intelligentization and high-endization are inevitable directions for the development of advanced manufacturing industries in the future. For example, cloud manufacturing, smart manufacturing, and the Internet of Things are products of advanced manufacturing intelligence.

The advanced manufacturing industry continuously optimizes and upgrades the products so that they are both sophisticated and highly productive and able to respond to changing user needs. And can make the redundant part of the production process be streamlined, and ultimately achieve the best results in all aspects of production including market supply and marketing. Traditional manufacturing is produced at the expense of the environment. The advanced manufacturing industry emphasizes the recycling of clean production and resources. Taking into account the natural environment and social efficiency, the products provided are characterized by no pollution, low energy consumption, and recyclability. Through the green revolution of the entire industrial production process from the design, manufacture, marketing, and circulation processing of 
manufacturing industries, the sustainable development of the manufacturing industry is realized.

\section{The Enlightenment Brought to China by the Foreign Advanced Manufacturing Development Policy}

The huge potential of China's advanced manufacturing market provides a broad market space for the development of advanced manufacturing. However, compared with advanced manufacturing countries and regions, domestic advanced manufacturing technology research and development and market expansion are still not balanced. In addition, the low numerical control rate of technical equipment in industries related to advanced manufacturing cannot meet the market demand for medium and high-end advanced products. Looking at the competition and development of foreign advanced manufacturing industries, facing the gradual integration of two advanced manufacturing markets, both foreign and domestic, How to integrate the decentralized enterprise resources according to the market demand of the domestic advanced manufacturing industry and form its own technological advantage in the advanced manufacturing industry as soon as possible has become an urgent issue for the manufacturing industry in China.

Advancing Technological Innovation in Advanced Manufacturing Industry to Improve Enterprise's Innovation Ability. China's advanced manufacturing enterprises should make full use of market resources and let the market mechanism advance the continuous industrialization of advanced manufacturing. Linking advanced manufacturing technology with industrialization, continuously increasing product added value, creating conditions for domestic industrial restructuring and upgrading, attracting more foreign advanced manufacturing innovation resources, and creating more opportunities for the development of advanced manufacturing in China . Promote the integration of advanced manufacturing technology introduction and innovation, increase the comprehensive competitive advantage of advanced manufacturing companies, rely on the existing resource advantages of Chinese enterprises, and break the boundaries between industries and enterprises. Constantly expanding the industrial chain, giving certain importance to corporate investment and research and development of new technologies and industrialization.

The Chinese government must play a guiding role in the development of advanced manufacturing industries. We must rely on major projects and combine production, education and research to cultivate the scientific research and innovation capabilities of enterprises. On the one hand, through the government's guidance and encouragement of major projects, it provides enterprises with a development platform to guide the healthy development of China's advanced manufacturing companies and enhance their overall competitiveness. On the other hand, attracting high-level professional talents to gather projects to break the "shackles" of science and technology transformation in universities and promote the integration of production, education and research. The government must continuously strengthen the leading position and role of innovation in advanced manufacturing enterprises, and form a group of innovative leading enterprises with international competitiveness to support the healthy development of small and medium-sized enterprises. Build an enterprise-led industrial technology research and development system, promote the application and industrialization of results with core intellectual property rights, cultivate and develop strategic emerging industries, and upgrade the overall level of innovation in advanced manufacturing.

Strengthen Support for Key Areas and Accelerate the Conversion of Results. "Made in China 2025" in the context of the specific conditions of our country, has identified the ten major areas of advanced manufacturing manufacturing. To achieve sustainable technological innovation and transformation of achievements in the key areas of advanced manufacturing is the focus that our government should focus on. To promote technological breakthroughs in key areas, we must formulate policies and measures to guide the development of the industry in light of China's specific national conditions and concentrate on solving key problems. Guide the development of advanced manufacturing to the high end and original direction of the value chain, avoiding disordered competition and low-end redundant construction. In addition, for key areas, it is necessary to strengthen government financial support and promote continuous innovation in the 
advanced manufacturing industry.

At this stage, the cycle of transformation of scientific research results is getting shorter and shorter. If a scientific research result does not translate into productivity within the conversion cycle, its economic potential will quickly decline. The U. S. Advanced Manufacturing Research Center has integrated scientific research institutions, companies, and government resources, and has achieved seamless integration of $R \& D$ and application, and has promoted the industrialization of innovative results. At present, the conversion rate of scientific research in China is obviously low, only about $10 \%$, lower than the average level of $40 \%$ in developed countries, and even lower than the level of $80 \%$ in the United States. In promoting the integration of production, education and research, "Made in China 2025" also made a useful attempt. A group of manufacturing innovation centers will be formed around the major common needs of the transformation and upgrading of key industries and the development of new generation information technology and other fields, focusing on industrial fundamentals and common key technologies for R\&D and achievement industrialization. If you want to further research and solve the problems of science and technology in economic and industrial development, the government needs to build a modern industrial system, cultivate a series of strategic emerging industries, and develop modern service industries. This will promote the transfer and transformation of scientific and technological achievements, and promote the jump of industries and products to the mid-to-high end of the value chain.

Improve the Advanced Manufacturing Personnel Training and Introduction Mechanism. The development of advanced manufacturing is inseparable from talented people. The gap between China's advanced manufacturing industry and developed countries in Europe and the United States lies mainly in the talents. The lack of senior management personnel, senior engineering and technical personnel, and high-quality skilled workers in China is the major bottleneck restricting the development of China's advanced manufacturing industry. The competition in advanced manufacturing has become increasingly fierce in recent years, and competition will ultimately be attributed to the competition for talents. The United States will focus on talent cultivation in its development strategy. Therefore, in addition to providing support in terms of policies, the Chinese government should adopt a more flexible approach in the development of advanced manufacturing, and actively establish various talent platforms. Such as talent exchange platform and introduction platform, personnel training platform, especially the training platform for innovative talents, use these platforms to carry out the introduction and cultivation of advanced manufacturing talents.

The government should adopt more flexible preferential policies to create a favorable environment that can attract talents, use talents, and retain talents. We must vigorously introduce talents in advanced technology, management, and other fields that are needed for advanced manufacturing, and encourage domestic and foreign advanced technical personnel to invest in China. . In particular, we must focus on the construction of advanced manufacturing bases, vigorously attract and employ high-level talents at home and abroad, and accelerate the building of suitable international and domestic talents. In addition, according to the development of the advanced manufacturing industry, relevant courses and research directions are offered in colleges and universities. The school selects a group of outstanding scientific and technological personnel to study abroad, study for a degree or go to domestic universities and research institutes for systematic learning. Establish a flexible employment mechanism and encourage enterprises to introduce talents in terms of policies. Actively build a talent flow platform and green channels inside and outside the province, establish information systems for overseas students and senior talents in developed regions, establish overseas talent pools based on the needs of domestic advanced manufacturing industries, and attract talented people to return home to start businesses.

Promote the Development of Advanced Manufacturing Clusters. Industrial clusters refer to the grouping of a group of interconnected companies, suppliers, associated industries, and specialized systems and associations within a specific area. Through this type of regional agglomeration, effective market competition has been established, and specialized production factors have been optimized to gather places so that enterprises can share regional public facilities, market environment and external economy, and reduce information exchange and logistics costs. 
Form regional agglomeration effect, scale effect, external effect and regional competitiveness. In close connection with the market orientation, government departments should give full play to their guiding role and guide the rational distribution of various industries with the industrial cluster development plan. Give full play to the guiding role of the government, attract advanced manufacturing companies at home and abroad to settle in, increase financial support for basic supporting facilities and advanced demonstration areas in industrial clusters, and take advantage of new financial financing platforms to promote the development of China's advanced manufacturing enterprises and gradually expand.

Promote the spatial concentration of advanced manufacturing enterprises in China and promote urbanization. In accordance with the functional requirements and comparative advantages of each region, administrative divisions should be broken down, overall planning and layout should be optimized, resource allocation should be optimized, industrial agglomeration should be guided, and rationalization of China's advanced manufacturing layout should be promoted. Focusing on cultivating and supporting a group of leading enterprises to enable them to quickly scale up and create brands, and become the core of the development of advanced manufacturing clusters, thus enhancing the overall competitiveness of China's advanced manufacturing industry. It is necessary to strengthen planning and guidance, taking leading enterprises as the main body, relying on industrial agglomeration areas as the basis, and in accordance with the requirements of the industrial division of labor, targeted introduction of large enterprises. To develop core industrial clusters, increase the degree of industrial agglomeration, and create a large enterprise group as soon as possible to drive the further development of related enterprises.

\section{Conclusion}

China's advanced manufacturing industry should combine its own characteristics to form distinctive development. As people continue to deepen the research and application of advanced manufacturing, in the new century, it will get greater development and growth, in order to improve the company's international competitiveness and technological innovation capabilities. Policy support centered on technological advancement, technological innovation and enhanced competitiveness can fundamentally solve the impetus and vitality of industrial development. It is the only way for China to become a manufacturing power from a big manufacturing country.

\section{Acknowledgements}

(WZ2017Y10) Manufacturing Industry Development Research Center on Wuhan City Circle, Jianghan University

\section{References}

[1] YuanyuanWang . The United States to promote the development of advanced manufacturing policy, experience and inspiration [J]. Asia-Pacific economy, 79-83(2017).

[2] Hong Jiang, Yujie Du , Yihe Liu . Research on the development policy of advanced manufacturing industry at home and abroad [J]. New Materials Industry, 44-46(2016).

[3] Qingran Guo. Research on the countermeasures to promote the construction of advanced manufacturing provinces in Henan Province [J]. Journal of Henan Institute of Science and Technology, 1-6(2015).

[4] Li Feng. Research on innovation policy based on policy elements in the United States [D]. University of Electronic Science and Technology, (2016).

[5] Yang Pan,Ruyi Luo. The Enlightenment of Advanced Manufacturing Development Policies in Developed Countries to Hangzhou[J]. Hangzhou Science and Technology,56-60(2014).

[6] Yanjun Liu. Study on the policy guarantee of advanced manufacturing industry in Jiangmen City[J]. Northern Economy and Trade, 57-58(2011). 
